\title{
Characterization of resistance to the wheat stem sawfly in spring wheat landrace accessions from targeted geographic regions of the world
}

\author{
Author: Andrea C. Varella, David K. Weaver, Jason \\ P. Cook, Nancy K. Blake, Megan L. Hofland, Peggy \\ F. Lamb, and Luther E. Talbert
}

The final publication is available at Springer via http://dx.doi.org/10.1007/s10681-017-1945-x

Varella, Andrea C. , David K. Weaver, Jason P. Cook, Nancy K. Blake, Megan L. Hofland, Peggy F. Lamb, and Luther E. Talbert. "Characterization of resistance to the wheat stem sawfly in spring wheat landrace accessions from targeted geographic regions of the world." Euphytica 213, no. 7 (July 2017): 1-11. DOI: 10.1007/s10681-017-1945-x.

Made available through Montana State University's $\underline{\text { ScholarWorks }}$ scholarworks. montana.edu 


\title{
Characterization of resistance to the wheat stem sawfly in spring wheat landrace accessions from targeted geographic regions of the world
}

Andrea C. Varella ${ }^{1}$, David K. Weaver ${ }^{2}$, Jason P. Cook ${ }^{1}$, Nancy K. Blake ${ }^{1}$, Megan L. Hofland ${ }^{2}$, Peggy F. Lamb $^{3}$, Luther E. Talbert ${ }^{1}$

1. Department of Plant Sciences and Plant Pathology, Montana State Univ., Bozeman, MT 59717, USA

2. Department of Land Resources and Environmental Sciences, Montana State Univ., Bozeman, MT

59717, USA

3. Department of Research Centers, Montana State Univ., Bozeman, MT 59717, USA

Corresponding author: Luther E. Talbert, email: usslt@montana.edu, phone: (406) 994-5060

\begin{abstract}
Plant landraces have long been recognized as potential gene pools for biotic and abiotic stressrelated genes. This research used spring wheat landrace accessions to identify new sources of resistance to the wheat stem sawfly (WSS) (Cephus cinctus Norton), an important insect pest of wheat in the northern Great Plains of North America. Screening efforts targeted 1,409 accessions from six geographical areas of the world where other species of grain sawflies are endemic or where a high frequency of accessions possesses the resistance characteristic of solid stems. Resistance was observed in approximately $14 \%$ of accessions. Half of the lines displayed both antixenosis and antibiosis types of resistance. Among the resistant accessions, $41 \%$ had solid or semi-solid stems. Molecular genetic screening for haplotypes at the solid stem QTL, Qss.msub.3BL, showed that $15 \%$ of lines shared the haplotype derived from 'S-615', the original donor of the solid stem trait to North American germplasm. Other haplotypes associated with solid stems were also observed. Haplotype diversity was greater in the center of origin of wheat. Evaluation of a representative set of resistant landrace accessions in replicated field trials at four locations over a three year period identified accessions with potential genes for reduced WSS infestation, increased WSS mortality, and increased indirect defense via parasitoids. Exploitation of distinct types of plant defense will expand the genetic diversity for WSS resistance currently present in elite breeding lines.
\end{abstract}

Keywords: Antibiosis, antixenosis, Cephus cinctus, genetic diversity, solid stem. 
Introduction Elite crop plants are often more susceptible to insect pests than their wild progenitors and landraces, due to a reduction in plant defense caused by domestication, artificial selection and breeding (Chen et al. 2015; Davila-Flores et al. 2013; Rosenthal and Dirzo 1997). For this reason, landrace accessions have been routinely mined for insect resistance traits in several crop species (Arnason et al. 1994; Laamari et al. 2008; Liu et al. 2009; Pelgrom et al. 2015; Valdez et al. 2012). Despite their value as genetic resource, mining plant defense traits in landraces is not an easy task, mainly because of the sheer number of accessions stored in germplasm repositories. A targeted geographical screening approach of landrace accessions was shown to be more successful, because geography underlies plantinsect interactions (El Bouhssini et al. 2011; Chen et al. 2015). Thus searching for new sources of insect resistance in geographic regions of the world where a plant species and its wild progenitors shared the longest evolutionary history with an insect pest can increase the likelihood of success.

Several species of grass sawflies in the family Cephidae infest wheat and other cultivated cereals throughout the world. Some of the most important species are in the genus Cephus. In North America, on the Canadian Prairies and the Northern Great Plains this is Cephus cinctus Norton, a native species also referred to as the wheat stem sawfly (WSS), which likely adapted to wheat from grass hosts already present in the prairie ecosystem shortly after tillage first began in the 1800s (Beres et al. 2011; Lesieur et al. 2016). In east Asia, Cephus fumipennis Eversmann is the native and dominant species that infests cereal crops (Chen et al. 2004), while in Western Europe, North Africa and the Middle East, Cephus pygmaeus (L.), the European wheat stem sawfly, is the main pest of cereals (Shanower and Hoelmer 2004). In Eastern North America, the cosmopolitan C. pygmaeus is an introduced species that is infrequently encountered due to successful classical biological control using the parasitoid Collyria calcitrator (Gravenhorst) (Shanower and Hoelmer 2004). The life cycles of these closely related species of sawflies and the damage caused by their interaction with wheat are indistinguishable. Females lay eggs in the stem, where the larvae feed on plant tissue reducing grain quality and yield (Morrill et al. 1992, 1994). Prior to plant senescence, mature larvae cut a groove around the base of the stem just above their overwintering chamber. Cut stems lodge and are not harvested (Criddle 1922). Areas of the world infested by $C$. pygmaeus represent some of the earliest instances of wheat cultivation. Thus, landraces collected from these areas have been under pressure from wheat stem sawflies since the dawn of wheat domestication, and their wild progenitors before that.

Research on C. pygmaeus in the 1920s revealed that less damage was caused in plants that had stems filled with pith, referred to as solid stems (Schegolev 1926). In the following decade, screening efforts identified a Portuguese landrace accession, S-615, carrying the solid stem trait (Kemp 1934). This 
accession was used to develop 'Rescue' (Cltr12435), the first solid-stemmed wheat variety (Platt et al. 1948). Stem solidness was shown to lessen plant damage by acting as a physical barrier reducing WSS egg deposition, larval movement and survival (Holmes and Peterson 1962; Wallace and McNeal 1966). As might be expected, the solid stem trait also provided resistance to $C$. fumipennis (Chen et al. 2004). In the 1950's, another screening effort involving 14,000 landrace accessions was undertaken by the USDAARS. Unfortunately, published information from these trials is sparse and lack of follow-up was probably related to the identification of solid stems as a simply inherited target for selection. Over the last six decades, the solid stem trait has been the base for WSS integrated pest management (Beres et al. 2011). The trait is conveniently measured in breeding programs at or near plant maturity.

The prevalence of solid stems in wheat from areas of the world with historic infestations of wheat stem sawflies, coupled with a limited understanding of its genetic basis, has impeded the identification of new sources of resistance. Recent research has elucidated the genetic architecture of the solid stem trait. Solid stems in hexaploid wheat cultivars is controlled by the solid stem quantitative trait locus (QTL), Qss.msub-3BL, which accounts for 70\% of the genetic variation (Cook et al. 2004; Sherman et al. 2010; Kalous et al. 2011; Varella et al. 2015), and the allele for solid stems traces to landrace S-615. This locus has also been identified in durum wheat (T. turgidum var. durum) and is referred to as SSt1 (Houshmand et al. 2007). Varella et al. (2016) identified a source of resistance in the hexaploid wheat cultivar 'Conan' (PI607549) (WestBred, LLC). Resistance in Conan was due to both antibiosis, whereby the plant had a deleterious effect on pest development and survival, and antixenosis, whereby the plant had a deleterious effect on colonization by the pest. The resistance allele was also mapped to Qss.msub-3BL, and conferred high stem solidness early in plant development when WSS females are ovipositing and a low level of stem solidness at maturity. Cook et al. (2017) showed that the allele for early stem solidness had a different haplotype based on SNP markers than either the S-615-derived solid stem allele or the common alleles for hollow stems.

Besides the use of solid stem cultivars for WSS control, integrated pest management for this insect pest also involves enhancement of natural biological control. In wheat fields of Western North America, WSS is killed by two specialist congeneric larval parasitoids, Bracon cephi (Gahan) and B. lissogaster Muesebeck (Morrill et al. 1994, Weaver et al. 2004; 2005, Cárcamo et al. 2012), while in other regions of the world, C. pygmaeus and C. fumipennis are mainly killed by egg-larval parasitoids of the genus Collyria (Wahl et al. 2007, Shanower and Hoelmer 2004). Attempts at classical biological control of WSS using Collyria coxator (Villers) from C. pygmaeus (reviewed in Shanower and Hoelmer 2004) and Collyria catoptron (Wahl) from C. fumipennis failed due to host incompatibility (Rand et al. 
2016a), even with favorable attributes for success (Rand et al. 2016a, b). An advantage of braconid species is that they kill damaging larvae, reducing yield loss (Buteler et al. 2008), while egg-larval parasitoids do not kill until the next crop season (after WSS larvae have cut the stem) and ongoing damage is not attenuated. Several other parasitoid species also kill WSS in feral grasses, but these are generalist parasitoids (Ainslie 1929). However, there are records of other species of Braconidae occurring in varying numbers in wheat fields infested by both C. pygmaeus (reviewed in Shanower and Hoelmer 2004) and C. fumipennis (Chen et al. 2004). Indirect defense due to braconid parasitoids is a desirable trait that can be readily detected during stem dissections, but only if the ambient populations of WSS and these parasitoids are both abundant.

The discovery of resistance unassociated with a high degree of stem solidness, coupled with the development of haplotype profiles for the known resistance gene, provides a basis for determining the potential novelty of newly identified sources of WSS resistance. In addition, research over the past decades has identified areas of the world most heavily impacted by wheat stem sawflies. The renewed interest in finding new types of resistance to WSS prompted a targeted screening of wheat landrace accessions from six distinct geographical regions of the world. A detailed characterization of WSS infestation, larval mortality and larval mortality due to parasitism allowed for identification of wheat landrace accessions showing antixenosis and/or antibiosis, as well as accessions displaying indirect plant defense characterized by increased recruitment of parasitoids. Resistant landrace accessions were genetically screened for the solid stem QTL, Qss.msub.3BL, to identify resistant accessions carrying the hollow stem haplotype for Qss.msub.3BL or other unique haplotypes, which may display resistance due to mechanisms other than stem solidness. This research lays the basis for a comprehensive discovery of novel direct and indirect defense genes for WSS resistance in wheat.

\section{Materials and methods}

Landrace accessions

To maximize the likelihood of identifying new genes for WSS resistance, selection of landrace accessions targeted geographical areas of the world where wheat stem sawflies are known to be endemic or where a high frequency of landrace accessions have been shown to possess the resistance characteristic of solid stems (Smith 1961; Wallace and McNeal 1966; Wallace et al. 1969; Damania et al. 1997; Chen et al. 2004; Frolov and Sanlich 2004; Hoelmer and Shanower 2004; Shanower 2008; Korkmaz et al. 2010). In total, seeds from 1,409 hexaploid wheat (Triticum aestivum L.) landrace accessions were obtained from 
the USDA-ARS National Small Grains Collection (NSGC) (Aberdeen, ID). Accessions originated from 30 countries located in South/Central/East Asia $(n=606)$, North Africa $(n=107)$, Europe $(n=35)$, Iberian Peninsula ( $n=281)$, Levant ( $n=215)$, and Persian Gulf Region $(n=165)$.

Screening of landraces in WSS-infested sites

Landraces were planted in late April, in the midst of stubble from a previous WSS-infested wheat crop, at sites with a history of WSS infestation located near Amsterdam, MT, USA, in 2012, 2014, and 2015, and at a second site near Loma, MT, USA, in 2013. Each landrace accession was screened in a single year. Plots consisted of 10 seeds per entry planted in individual hills with spacing of $0.8 \mathrm{~m}$ between adjacent hills. Trials were conducted using an augmented design in which entries were unreplicated and checks were replicated in each block. Check entries included the WSS susceptible varieties, 'Reeder' (PI613586) and 'McNeal' (PI574642), and the solid-stemmed WSS resistant variety, 'Choteau' (PI633974). Accessions were scored for stem solidness at maturity by rating a cross-section of the third or fourth internode of a stem using a 1 (completely hollow) to 5 (completely solid) scale, as described by Varella et al. (2016). At maturity (Zadoks growth stage 99, ripening), plots were visually evaluated for percent cut stems. Accessions that had percent cut stems less than the susceptible check entries were collected and dissected to determine WSS infestation, larval mortality, and parasitism for further characterization as per Talbert et al. (2014). Accessions not harvested were characterized as susceptible. Harvested accessions showing WSS infestation below 25\% were characterized as displaying antixenosis, accessions showing WSS mortality (due to plant resistance) over $25 \%$ were characterized as displaying antibiosis, and accessions that fit both criteria were characterized as displaying both antixenosis and antibiosis. Accessions showing parasitism levels over $45 \%$ were characterized as displaying indirect plant defense. Landraces that headed after the susceptible check varieties (Julian heading date of $191 \mathrm{~d}$ ) were considered late heading and were not included in the resistant group as they may have missed the WSS flight period and escaped infestation.

\section{Replicated trial with selected landrace accessions}

Based on field data from the first year of the experiments, twelve resistant wheat landrace accessions from Iran $(n=1)$, Japan $(n=1)$, Tajikistan $(n=1)$, Turkey $(n=8)$, and Turkmenistan $(n=1)$ were selected to be used in replicated trials. Selection of accessions aimed to capture multiple resistance types (e.g. antibiosis, antixenosis, indirect defense due to parasitoids) present at distinct geographic regions of the world. A susceptible accession from Nepal was included in the trial as a susceptible check along with 
Reeder and McNeal. The stem dissection procedure from the first year of experiments revealed variation in WSS reaction between different plants within a hill plot, suggesting the presence of genetic heterogeneity. Such variation was observed only for some accessions, from which seeds from different heads were selected for further screening to increase the chances of finding different alleles conferring resistance to WSS. Therefore, a total of 23 unique resistant lines were evaluated in replicated trials. Accessions were planted in hill plots as described above in Amsterdam, MT, USA, in 2014 and 2015, and at a second site near Loma, MT, USA, in 2013 and 2014. Trials were conducted in a randomized complete block design with four replications in 2013, and two replications in 2014 and 2015. At maturity (Zadoks growth stage 99, ripening), accessions were collected and dissected to determine WSS infestation level, larval mortality, and parasitism.

DNA preparation and Kompetitive Allele Specific PCR (KASP) assay

Genomic DNA was isolated from young leaf tissue using a 96-well plate protocol (Chao and Somers, http://maswheat.ucdavis.edu/PDF/DNA0003.pdf, accessed February 2017) modified from Pallotta et al. (2003). Five KASP markers, BS00022441, BS00079029, IWB72657, BS00073411, and BS00074345 were used to characterize the haplotype diversity for the solid stem QTL, Qss.msub.3BL, as identified by Cook et al. (2017). KASP assays were performed following the protocol and conditions given in the KASP manual (http://www.lgcgroup.com/) as described by Cook et al. (2017). Check entries included the hollow-stemmed variety, McNeal, semi-solid stemmed variety, Conan, and solid-stemmed variety, Choteau.

Statistical analysis

Results from the replicated trial with selected landrace accessions were analyzed using PROC GLIMMIX in SAS 9.3 (SAS Institute Inc. 2012). Variables were modelled using the LINK=LOGIT function and denominator degrees of freedom were determined using the KENWARDROGER option. Plant ID was considered a fixed effect and replication within environment was a random effect.

\section{Results}

Phenotypic variation for WSS reaction in wheat landrace accessions Natural WSS infestation was variable across the four experimental years. The highest levels of infestation were recorded in 2015 , when the mean value was $22 \%$ and variation among lines ranged 
from 0 to 72\%. The lowest infestation levels were recorded in 2014, when infestation ranged from 0 to $48 \%$ with a mean of 14\% (data not shown). From the 1,409 landrace accessions screened between 2012 and 2015, 204 (14.47\%) showed resistance to WSS. The stem dissection procedure allowed for characterization of accessions as presenting antibiosis, antixenosis, or indirect defense due to parasitoids (Table 1). Half of the resistant lines showed a combination of both antibiosis and antixenosis, 19.6\% showed only antixenosis, and $26.5 \%$ showed only antibiosis. Resistance type was not determined in $5.4 \%$ of accessions due to an insufficient number of stems $(<15)$. Approximately $43 \%$ of the resistant accessions came from the Levant (25\%) and Persian Gulf Region (18.13\%) regions, though resistant accessions were found in all targeted regions of the world (Table 1). Among all 204 resistant accessions, WSS infestation ranged from 0 to $72 \%$, WSS parasitism and mortality ranged from 0 to $100 \%$, and stem cutting ranged from $0 \%$ to $44 \%$ (Table 2). As stated in the methods section, the range of variation for WSS infestation among accessions displaying antixenosis was 0 to $25 \%$, whereas variation in WSS mortality for accessions displaying antibiosis was 25 to $100 \%$, meaning that some accessions, such as PI262628 and PI537968, which showed high levels of WSS infestation (68 and 48\%, respectively), were classified resistant because they caused high levels of WSS mortality (antibiosis) (64.7 and 67\%, respectively). Susceptible accessions accounted for $37.5 \%$ of the screened material, while late heading and missing (no germination) accounted for $39.2 \%$ and $9.9 \%$ of accessions, respectively (Table 1 ).

Evaluation of haplotypes corresponding to the Qss.msub.3BL region in resistant accessions The solid stem trait was commonly observed among the resistant landrace accessions, with $41 \%$ of the resistant accessions showing either solid or semi-solid stems. Since stem solidness is known to cause antibiosis and antixenosis (Varella et al. 2017), all resistant accessions were screened for the major solid stem QTL, Qss.msub.3BL haplotype. There were 17 Qss.msub.3BL haplotypes among the resistant accessions. The solid stem haplotype identified in Northern Great Plains WSS resistant varieties and originally derived from S-615 (haplotype A from Cook et al. 2017) was found in 29 accessions from the Iberian Peninsula (Spain and Portugal), North Africa (Morocco), Levant (Turkey and Israel), Persian Gulf Region (Iran), Europe (Greece), and South/Central/East Asia (Turkmenistan and Georgia), whereas the haplotype conferring early stem solidness (haplotype B) was present in two accessions from Iran (Table 3). The haplotype for hollow stems present in the susceptible wheat variety McNeal (haplotype C) was present in 82 landrace accessions. Among these 82 accessions, 31 displayed antibiosis, 14 displayed antixenosis, and 34 had both types of resistance. Among the resistant landrace accessions selected for the replicated trials, there were 7 haplotypes (Table 4). In general, seeds from different heads of an 
accession had the same Qss.msub.3BL haplotype. Exceptions were PI639349-1 and PI639349-4, which had haplotypes AB and T, respectively, and PI565386-1, PI565386-2, PI565386-3, which had haplotypes $A D, C$, and $A B$, respectively, as indicated by Cook et al. (2017) (Table 4). After multiple genotyping attempts, 12 landrace accessions showed no amplification for at least one KASP assay and, therefore, were excluded from the haplotype results. A complete list of resistant accessions, their haplotypes and resistance type is available in Supplementary Table 1.

Replicated trials with selected landrace accessions

Mean values of WSS infestation across replicated trials ranged from 13.1 to $46.9 \%$, with six of 12 accessions showing significantly $(p<0.05)$ less infestation than the susceptible check from Nepal (Table 4). Stem cutting was significantly $(p<0.05)$ reduced in all resistant accessions and mean values ranged from 0.8 to $11.3 \%$. One of the Turkish accessions had significantly $(p<0.05)$ more parasitism than the susceptible check from Nepal and two accessions from Turkey and Turkmenistan showed significantly ( $p$ $<0.05$ ) higher WSS larval mortality (Table 4). When compared with susceptible wheat varieties, Reeder and McNeal, landrace accessions PI623445-2 ( $t=2.03, p=0.04$ ), PI382150-2 ( $t=2.20, p=0.03$ ), PI576680-2 $(t=2.24, p=0.03)$ and PI576680-3 $(t=2.05, p=0.04)$, PI576688-4 $(t=2.12, p=0.04)$, PI166471-1 $(t=2.10$, $p=0.04), \mathrm{PI} 166477-2$ ( $t=2.68, p=0.008), \mathrm{PI} 178055-1(t=2.75, p=0.007), \mathrm{PI} 65386-2(t=2.11, p=0.04)$ and PI565386-3 ( $t=2.49, p=0.01)$ had significantly more indirect defense due to parasitism by braconids. Mean parasitism of WSS in Reeder and McNeal was $24.60 \%$. In general, seeds from different heads of an accession showed similar values for WSS infestation, stem cutting, parasitism, and larval mortality. Exceptions were values for stem cutting for PI565386-1, which was significantly higher $(p<0.05)$ than PI565386-2 and PI565386-3, and value for parasitism in PI178055-1, which was significantly higher ( $p<$ 0.05) than PI178055-2 (data not shown).

\section{Discussion}

Phenotypic variation was observed for all traits evaluated, highlighting the potential of using landrace accessions for improving WSS resistance in North American wheat breeding programs. Previous studies aimed at identifying landrace accessions showing resistance to WSS reported resistance in approximately $10 \%$ of the screened material (Wallace et al. 1969). In the present study, resistance was identified in about $14 \%$ of the screened material, probably because of the targeted geographical screening approach used to select accessions (Damania et al. 1997, El Bouhssini et al. 2011; Chen et al. 
2015). Resistance was predominant in areas where C. pygmaeus is endemic, which is consistent with the expectation that sources of resistance would likely be found in geographical regions where plant and insect species shared the longest evolutionary history. Also consistent with this generalization is the observation that the Levant, which is a center of origin for wheat, harbors the greatest diversity of Qss.msub-3BL haplotypes $(\mathrm{n}=10)$ among WSS resistant accessions. The Levant was previously reported to harbor the greatest diversity of Qss.msub-3BL haplotypes in tetraploid wheat landrace accessions (Cook et al. 2017). Indeed, the rare haplotype B associated with early stem solidness expression and pith retraction (Varella et al. 2016) was only observed in the Persian Gulf region, also a center of origin for wheat.

The majority of the resistant accessions showed both antixenosis and antibiosis. Some insect resistance traits, such as stem solidness, simultaneously affect insect biology and behavior (Varella et al. 2017), while others may affect one or the other. Mechanisms of resistance associated with antibiosis could have reduced plant palatability (Michell et al. 2016) and increased production of anti-nutritive substances (Tamiru et al. 2015), increased egg mortality through hypersensitive response (Hilker and Meiners 2002), or increased larval mortality due to presence of toxic compounds (Fürstenberg-Hägg et al. 2013) and physical barriers (Michell et al. 2016). Likewise, antixenosis could have been caused by many mechanisms of resistance involving volatile compounds associated with host plant selection (Weaver et al. 2009) and non-volatile deterrent compounds that discourage probing and oviposition (Tamiru et al. 2015). Further studies will be necessary to determine the mechanisms of resistance displayed by these landrace accessions. The fact that antibiosis and antixenosis were often expressed in the same accession suggests that multiple resistance genes might exist in a single accession. Alternatively, as indicated by Varella et al. (2017) for the allele conferring early stem solidness, both types of resistance might be conferred by the same gene. Either scenario would provide parents for introgressing resistance into breeding materials.

The genetic characterization of the solid stem QTL, Qss.msub-3BL, revealed 82 resistant accessions with the hollow stem haplotype C. Most of these had stem solidness scores below 2 (hollow), although there were a few exceptions, such as accessions PI499971 and PI623599 that showed scores of 5 (solid) and 3.5 (semi-solid), respectively. These exceptions may harbor other minor genes for stem solidness (Larson and MacDonald 1962; Lanning et al. 2006; Varella et al. 2015). On the other hand, hollow-stemmed accessions carrying haplotype $\mathrm{C}$ have great potential for harboring new mechanisms of resistance to WSS. The effects of haplotypes A, B, and C on stem morphology and WSS biology and behavior have already been investigated (Varella et al. 2016; Varella et al. 2017). Such investigation has 
provided evidence that haplotype A, derived from S-615 and commonly found in North American solidstemmed varieties, might not provide the best WSS control (Varella et al. 2016; Varella et al. 2017).

Besides antibiosis and antixenosis, resistance to the WSS can be provided by indirect plant defense mechanisms, which result in increased recruitment of parasitoids. Two species of native parasitoids, B. cephi and B. lissogaster, were identified inside wheat stem of landrace accessions. Therefore, despite differences in reproductive strategies shown by the dominant parasitoids species of WSS and the two congeners, results presented here indicate that the North American parasitoid species can successfully locate the WSS larvae in landrace accessions. By comparing WSS parasitism rates in landraces and wheat varieties, it was possible to identify accessions that were more efficient in recruiting parasitoids. This may be of value in enhancing the contributions of braconid species in the overall kill of $C$. pygmaeus and $C$. fumipennis by parasitoids. Crop domestication and artificial selection can disrupt tritrophic interactions and unintentionally reduce the effectiveness of natural enemies by negatively altering important cues used by predators and parasitoids for host location (Chen et al. 2015; Chen and Welter 2005; Wang et al. 2009). Thus, it is reasonable to speculate that some landraces might harbor genes or favorable alleles for indirect plant defense that were lost during domestication and artificial selection. These accessions may have the potential benefit of improving WSS control and enhancing our understanding of tritrophic interactions in wheat.

Within the North American wheat producing area there are three distinct genetic clusters of WSS, the Northern (Canada and central and eastern Montana), Southern (Wyoming, Nebraska, and Colorado), and Mountain (western Montana and Idaho) clusters (Lesieur et al. 2016). These distinct genetic groups could potentially show different responses to resistance genes and/or alleles. Also, high genetic diversity among clusters may facilitate the development of WSS populations that are adapted to resistant varieties (Lesieur et al. 2016). Thus, the development of WSS resistant varieties harboring multiple resistance genes might provide a more durable control strategy that could be implemented in a larger wheat producing area. Landrace accessions identified here should be a great source of multiple genes for resistance.

In conclusion, wheat landraces harbor phenotypic variation for WSS resistance that may be used in breeding programs to improve pest control. Exploitation of accessions displaying distinct types of plant defense may expand the genetic diversity for WSS resistance currently present in elite breeding lines. Furthermore, genetic resistance harbored by landraces was shown to go beyond the Qss.msub.3BL solid stem QTL, as multiple resistant accessions carried the hollow stem Qss.msub.3BL haplotype associated with susceptibility in North America. Accessions showed different types of host plant defense 
that were not genetically linked to the commonly used allele for solid stems. These accessions provide a basis for development of bi-parental populations to identify new QTL for WSS resistance for use in wheat breeding programs.

Acknowledgements This research was supported by grants from the Montana Wheat and Barley Committee and by USDA National Institute of Food and Agriculture awards 2017-67007-25939 and 2013-67013-21106.

\section{References}

Ainslie CN (1929) The western grass-stem sawfly - a pest of small grains. USDA. Bulletin No. 157, Washington, DC

Arnason JT, Baum B, Gale J, Lambert JDH, Bergvinson D, Philogene BJR, Serratos JA, Mihm J, Jewell DC (1994) Variation in resistance of Mexican landraces of maize to maize weevil Sitophilus zeamais, in relation to taxonomic and biochemical parameters. Euphytica 74:227-236

Beres BL, Dosdall LM, Weaver DK, Cárcamo HA, Spaner DM (2011) Biology and integrated management of wheat stem sawfly and the need for continuing research. Can J Entomol 143:105-125

Buteler M, Weaver DK, Miller PR (2008) Wheat stem sawfly infested plants benefit from parasitism of the herbivorous larvae. Agric For Entomol 10:347-354; Corrigendum 11:123

Cárcamo HA, Weaver DK, Meers SB, Beres BL, Mauduit AL (2012) First record of Bracon lissogaster (Hymenoptera: Braconidae) in Canada - a potentially important parasitoid of Cephus cinctus (Hymenoptera: Cephidae) in the prairies. Biocontrol Sci Technol 22:367-369

Cavanagh CR, Chao S, Wang S, Huang BE, Stephen S, Kiani S, Forrest K, Saintenac C, Brown-Guedira GL, Akhunova A, See D, Bai G, Pumphrey M, Tomar L, Wong D, Kong S, Reynolds M, da Silva ML, Bockelman $\mathrm{H}$, Talbert L, Anderson JA, Dreisigacker S, Baenziger S, Carter A, Korzun V, Morrell PL, Dubcovsky J, Morell MK, Sorrells ME, Hayden MJ, Akhunov E (2013) Genome-wide comparative diversity uncovers multiple targets of selection for improvement in hexaploid wheat landraces and cultivars. Proc. Natl. Acad. Sci. USA 110:8057-8062

Chen S, Hoelmer KA, Chen H, Liu A, Shanower TG (2004) A review of wheat stem sawfly (Hymenoptera: Cephidae) research in China. J Agr Urban Entomol 21:249-256

Chen YH, Welter SC (2005) Crop domestication disrupts a native tritrophic interaction associated with the sunflower, Helianthus annuus (Asterales: Asteraceae). Ecol Entomol 30:673-683

Chen YH, Gols R, Benrey B (2015) Crop domestication and its impact on naturally selected trophic interactions. Annu Rev Entomol 60:35-58 
Cook JP, Wichman DM, Martin JM, Bruckner PL, Talbert LE (2004) Identification of microsatellite markers associated with a stem solidness locus in wheat. Crop Sci 44:1397-1402

Cook JP, Blake NK, Heo H-Y, Martin JM, Waver DK, Talbert LE (2017) Phenotypic and haplotype diversity among tetraploid and hexaploid wheat accessions with potentially novel insect resistance genes for wheat stem sawfly. Plant Genome 10: doi:10.3835/plantgenome2016.03.0026

Criddle N (1922) The Western wheat-stem sawfly and its control. In: Dominion of Canada Dep Agric Pamphlet 6:3-8

Damania AB, Pacetti L, Qualset CO, Humeid BO (1997) Diversity and geographic distribution of stem solidness and environmental stress tolerance in a collection of durum wheat landraces from Turkey. Genet Resources and Crop Evol 44:101-108

Dávila-Flores AM, DeWitt TJ, Bernal JS (2013) Facilitated by natural and agriculture: performance of a specialist herbivore improves with host-plant life history evolution, domestication, and breeding. Oecologia 173:1425-1437

El Bouhssini M, Street K, Amri A, Mackay M, Ogbonnaya FC, Omran A, Abdalla O, Baum M, Dabbous A, Rihawi F (2011) Sources of resistance in bread wheat to Russian wheat aphid (Diuraphis noxia) in Syria identified using the Focused Identification of Germplasm Strategy (FIGS). Plant Breed 130:96-97

Frolov AN, Saulich MI (2004) Area of distribution and damage of the European wheat stem sawfly, Cephus pygmaeus L. http://www.agroatlas.ru/en/content/pests/Cephus_pygmaeus/map. Accessed 15 March 2017

Fürstenberg-Hägg J, Zagrobelny M, Bak S (2013) Plant defense against insect herbivores. Int J Mol Sci 14:10242-10297

Hilker M, Meiners T (2002) Induction of plant responses to oviposition and feeding by herbivorous arthropods: a comparison. Entomol Exp Appl 104:181-192

Hoelmer KA, Shanower TG (2004) Foreign exploration for natural enemies of Cephid sawflies. J Agric Urban Entomol 21:223-238

Holmes ND, Peterson LK (1962) Resistance of spring wheats to the wheat stem sawfly, Cephus cinctus Nort. (Hymenoptera: Cephidae) II. Resistance to the larva. Can Entomol 94:348-365

Houshmand S, Knox RE, Clarke FR, Clarke JM (2007) Microsatellite markers flanking a stem solidness gene on chromosome 3BL in durum wheat. Mol Breeding 20:261-270

Kalous JR, Martin JM, Sherman JD, Blake NK, Lanning SP, Talbert LE (2011) Phenotypic variation and patterns of linkage disequilibrium associated with introduced genes in spring wheat. Crop Sci 51:24662478

Kemp HJ (1934) Studies of solid stem wheat varieties in relation to wheat stem sawfly control. Scientific Agriculture 15: 30-38 
Korkmaz EM, Budak M, Hastaoglu Orgen S, Bagda E, Gencer L, Ulgenturk S, Basibuyuk HH (2010) New records and a checklist of Cephidae (Hymenoptera: Insecta) of Turkey with a short biogeographical description. Turk J Zool 34:203-211

Laamari M, Khelfa L, Coeur d'Acier A (2008) Resistance source to cowpea aphid (Aphis craccivora Koch) in broad bean (Vicia faba L.) Algerian landrace collection. Afr J Biotechnol 7:2486-2490

Lanning SP, Fox P, Elser J, Martin JM, Blake NK, Talbert LE (2006) Microsatellite markers associated with a secondary stem solidness locus in wheat. Crop Sci 46:1701-1703

Larson RI, MacDonald MD (1962) Cytogenetics of solid stem in common wheat: stem solidness of monosomic lines of the variety S-615. Can J Botany 37:365-378

Lesiuer V, Martin JF, Weaver DK, Hoelmer KA, Smith DR, Morrill WL, Kadiri N, Peairs FB, Cockrell DM, Randolph TL, Walters D, Bon MC (2016) Phylogeography of the wheat stem sawfly, Cephus cinctus Norton (Hymenoptera: Cephidae): implications for pest management. PLoS One 11(12):e0168370

Liu Y, Su C, Jiang L, He J, Wu H, Peng C, Wan J (2009) The distribution and identification of brown planthopper resistance genes in rice. Hereditas 146:67-73

Michell C, Brennan RM, Graham J, Karley AJ (2016) Plant defense against herbivorous pests: exploring resistance and tolerance traits for sustainable crop protection. Front Plant Sci 7:1132

Morrill WL, Gabor JW, Kushnak GD (1992) Wheat stem sawfly (Hymenoptera: Cephidae): damage and detection. J Econ Entomol 85:2413-2417

Morrill WL, Kushnak GD, Bruckner PL, Gabor JW (1994) Wheat stem sawfly (Hymenoptera: Cephidae) damage, rates of parasitism, and overwinter survival in resistant wheat lines. J Econ Entomol 87:13731376

Pallotta MA, Warner P, Fox RL, Kuchel H, Jefferies SJ, Langridge P (2003) Marker assisted wheat breeding in the southern region of Australia. In: Proc 10 ${ }^{\text {th }}$ Int Wheat Genet Symp, Paestum, Italy. 1-6 Sept. 2003. Istituto Sperimentale per la Cerealicoltura, Rome. Vol. 2, p.789-791

Platt AW, Farstad CW, Callenbach JA (1948) The reaction of Rescue wheat to sawfly damage. Sci Agric 28:154-161

Pelgrom KTB, Broekgaarden C, Voorrips RE, Bas N, Visser RGF, Vosman B (2015) Host plant resistance towards the cabbage whitefly in Brassica oleracea and its wild relatives. Euphytica 202:297-306

Rand TA, Waters DK, Shanower TG (2016a) Preliminary evaluation of the parasitoid wasp, Collyria catoptron, as a potential biological control agent against the wheat stem sawfly, Cephus cinctus, in North America, Biocontrol Sci Technol 26:61-71

Rand TA, Morrill WL, Runyon JB, Hoelmer KA, Shanower TG, Littlefield JL, Weaver DK (2016b) Assessing phenological synchrony between the Chinese sawfly, Cephus fumipennis, its egg-larval parasitoid, 
Collyria catoptron, and the North American sawfly, Cephus cinctus: Implications for biological control. Can Entomol 148:482-492

Rosenthal JP, Dirzo R (1997) Effects of life history, domestication and agronomic selection on plant defence against insects: evidence from maizes and wild relatives. Evol Ecol 11:337-355.

SAS Institute (2012) Base SAS 9.3 Procedures Guide, 2nd ed. SAS Inst. Inc., Cary, NC

Schegolev VN (1926) European sawfly (Cephus pigmaeus) and black sawfly (Trachelus tabidus) in Stavropol in 1925. Nakhichevan Agr Exp Sta (Rostov) Bul pp 8.

Shanower TG (2008) Wheat stem sawflies: Cephus cinctus Norton, Cephus pymaeus (L.) and Trachelus tabidus (F.) (Hymenoptera: Cephidae). In: Capinra JL (ed) Encyclopedia of Entomology, Kluer Acad Pub, Boston, MA

Shanower TG, Hoelmer KA (2004) Biological control of wheat stem sawflies: Past and future. J Agric Entomol 21:197-221

Sherman JD, Weaver DK, Hofland ML, Sing SE, Buteler M, Lanning SP, Naruoka Y, Crutcher F, Blake NK, Martin JM, Lamb PF, Carlson GR, Talbert LE (2010) Identification of novel QTL for sawfly resistance in wheat. Crop Sci 50:73-86

Smith RW (1961) Notes on parasites of the wheat stem sawfly, Cephus cinctus (L.) (Hymenoptera: Cephidae) from continental Europe. Canad Entomologist 9:714-717.

Talbert LE, Sherman JD, Hofland ML, Lanning SP, Blake NK, Grabbe R, Lamb PF, Martin JM, Weaver DK (2014) Resistance to Cephus cinctus Norton, the wheat stem sawfly, in a recombinant inbred line population of wheat derived from two resistance sources. Plant Breeding 133:427-432

Tamiru A, Khan ZR, Bruce TJA (2015) New directions for improving crop resistance to insect by breeding for egg induced defence. Curr Opin Insect Sci 9:51-55

Valdez VA, Byrne PF, Lapitan NLV, Peairs FB, Bernardo A, Bai G, Haley SD (2012) Inheritance and genetic mapping of Russian wheat aphid resistance in Iranian wheat landrace accession PI 626580. Crop Sci 52:676-682

Varella AC, Weaver DK, Sherman JD, Black NK, Heo H-Y, Kalous J, Chao J, Hofland ML, Martin JM, Kephart KD, Talbert LE (2015) Association analysis of stem solidness and wheat stem sawfly resistance in a panel of North American spring wheat germplasm. Crop Sci 55:2046-2055

Varella AC, Talbert LE, Hofland ML, Buteler M, Sherman JD, Blake NK, Heo H-Y, Martin JM, Weaver DK (2016) Alleles at a quantitative trait locus for stem solidness in wheat affect temporal patterns of pith expression and level of resistance to the wheat stem sawfly. Plant Breeding 135:546-551

Varella, AC, Weaver DK, Peterson RKD, Sherman JD, Hofland ML, Blake NK, Martin JM, Talbert LE (2017) Host plant quantitative trait loci affect specific behavioral sequences in oviposition by a stem-mining insect. Theor Appl Genet 130:187-197 
Wahl DB, Shanower TG, Hoelmer KA (2007) A new species of Collyria Schiødte (Hymenoptera: Ichneumonidae: Collyriinae), a parasitoid of Cephus fumipennis (Hymenoptera: Cephidae) in China, and potential biological control agent for Cephus cinctus in North America. J Kans Entomol Soc 80:43-50.

Wallace LE, McNeal FH (1966) Stem sawflies of economic importance in grain crops in the United States. USDA Tech. Bull. 1350. U.S. Gov Print Office, Washington, DC

Wallace LE, McNeal FH, Berg MA, Luginbill Jr. P (1969) Resistance of varieties of Portuguese wheat, Triticum aestivum L. em Thell., to the wheat stem sawfly. USDA-ARS 33-132, Washington, DC, 8pp

Wang XG, Nadel H, Johnson MW, Daane KM, Hoelmer K, Walton VM, Pickett CH, Sime KR (2009) Crop domestication relaxes both top-down and buttom-up effects on a specialist herbivore. Basic Appl Ecol 10:216-227

Weaver DK, Buteler M, Hofland ML, Runyon JB, Nansen C, Talbert LE, Lamb P, Carlson GR (2009) Cultivar preferences of ovipositing wheat stem sawflies as influenced by the amount of volatile attractant. J Econ Entomol 102:1009-1017

Weaver DK, Nansen C, Runyon JB, Sing SE, Morrill WL (2005) Spatial distributions of Cephus cinctus Norton (Hymenoptera: Cephidae) and its braconid parasitoids in Montana wheat fields. Biol Control 34:1-11

Weaver DK, Sing SE, Runyon JB, Morrill WL (2004) Potential impact of cultural practices on wheat stem sawfly (Hymenoptera: Cephidae) and associated parasitoids. J Agr Urban Entomol 21:271-287 
TABLES

Table 1 Geographical origin of spring wheat landrace accessions and their reaction to the wheat stem sawfly

\begin{tabular}{|c|c|c|c|c|c|c|c|c|}
\hline \multirow[t]{2}{*}{ Region } & \multirow[t]{2}{*}{ Countries } & \multirow{2}{*}{$\begin{array}{c}\text { No. } \\
\text { susceptible }\end{array}$} & \multirow{2}{*}{$\begin{array}{l}\text { No. late } \\
\text { heading }\end{array}$} & \multicolumn{5}{|c|}{ No. resistant ${ }^{a}$} \\
\hline & & & & $A X$ & $A B$ & $A X \& A B$ & UD & Total \\
\hline Europe & $\begin{array}{c}\text { Austria, France, } \\
\text { Germany, Greece, } \\
\text { Hungary, Italy, Sweden, } \\
\text { Switzerland, United } \\
\text { Kingdom }\end{array}$ & 14 & 17 & 0 & 1 & 3 & 0 & 4 \\
\hline Levant & Israel, Syria, Turkey & 43 & 120 & 8 & 9 & 28 & 6 & 51 \\
\hline North Africa & Algeria, Morocco & 46 & 8 & 8 & 6 & 13 & 1 & 28 \\
\hline
\end{tabular}

${ }^{\mathrm{a}} \mathrm{B}$, antibiosis; $\mathrm{AX}$, antixenosis; UD, undetermined 
Table 2 Range, mean, standard deviation, and coefficient of variation for traits associated with wheat stem sawfly resistance in landrace accessions resistant to this insect pest

\begin{tabular}{lcccc}
\hline \multicolumn{1}{c}{ Trait } & Range & Mean & $\begin{array}{c}\text { Standard } \\
\text { deviation }\end{array}$ & $\begin{array}{c}\text { Coefficient of } \\
\text { variation }\end{array}$ \\
\hline Stem solidness & $1-5^{\mathrm{a}}$ & 2.39 & 0.94 & 0.39 \\
WSS infestation (\%) & $0.00-72.00^{\mathrm{b}}$ & 19.44 & 14.59 & 0.75 \\
WSS parasitism (\%) & $0.00-100.00^{\mathrm{b}}$ & 31.51 & 27.56 & 0.87 \\
WSS mortality (\%) & $0.00-100.00^{\mathrm{b}}$ & 47.30 & 29.37 & 0.62 \\
Stem cutting (\%) & $0.00-44.00^{\mathrm{b}}$ & 3.28 & 5.60 & 1.70 \\
\hline
\end{tabular}

a Potential values range from 1 to 5

${ }^{b}$ Potential values range from 0.00 to 100.00 
Table 3 Summary of haplotype diversity for the solid stem QTL, Qss.msub.3BL, on wheat landrace accessions resistant to the wheat stem sawfly

\begin{tabular}{|c|c|c|c|c|c|c|c|c|c|}
\hline \multirow[b]{2}{*}{ Hap $^{a}$} & \multirow{2}{*}{$\begin{array}{c}\text { No. } \\
\text { Accessions }\end{array}$} & \multirow[b]{2}{*}{ Region $^{b}$} & \multicolumn{2}{|c|}{ Stem solidness } & \multicolumn{5}{|c|}{ KASP markers and molecular distances (cM) ${ }^{d}$} \\
\hline & & & Mean & Range $^{c}$ & $\begin{array}{c}\text { BS00022441 } \\
(136.3)\end{array}$ & $\begin{array}{c}\text { BS00073411 } \\
(140.5)\end{array}$ & $\begin{array}{c}\text { IWB72657 } \\
(143.3)\end{array}$ & $\begin{array}{c}\text { BS00079029 } \\
(144.7)\end{array}$ & $\begin{array}{c}\text { BS00074345 } \\
(144.7)\end{array}$ \\
\hline A & 29 & $E, I P, L, N A, P G R, A$ & 3.01 & $1.8-5.0$ & & & & & \\
\hline B & 2 & PGR & 2.23 & 2.2 & & & & & \\
\hline C & 82 & $E, I P, L, N A, P G R, A$ & 1.99 & $1.0-5.0$ & & & & & \\
\hline $\mathrm{E}$ & 1 & $A$ & 2.50 & 2.5 & & & & & \\
\hline J & 4 & $L, N A, A$ & 2.47 & $1.5-3.2$ & & & & & \\
\hline K & 5 & A & 1.8 & $1.1-2.2$ & & & & & \\
\hline M & 8 & L, NA & 2.42 & $2.1-2.8$ & & & & & \\
\hline $\mathrm{N}$ & 7 & L, NA, PGR & 2.30 & $1.0-4.6$ & & & & & \\
\hline $\mathrm{P}$ & 5 & L, A & 2.25 & $1.7-2.8$ & & & & & \\
\hline$S$ & 1 & PGR & 3.00 & 3.0 & & & & & \\
\hline $\mathrm{T}$ & 7 & $E, I P, L, A$ & 3.23 & $2.5-5.0$ & & & & & \\
\hline AA & 1 & IP & 4.00 & 4.0 & & & & & \\
\hline$A B$ & 9 & $I P, L, A$ & 2.44 & $1-5.0$ & & & & & \\
\hline$A C$ & 34 & IP, L, NA, PGR, A & 1.98 & $1-3.8$ & & & & & \\
\hline$A D$ & 3 & $I P, A$ & 2.22 & $1-3.3$ & & & & & \\
\hline $\mathrm{AE}$ & 2 & NA & 3.15 & $2.5-3.8$ & & & & & \\
\hline $\mathrm{AF}$ & 4 & $I P, L$ & 2.79 & $1.9-3.6$ & & & & & \\
\hline
\end{tabular}

aHaplotype denomination according to Cook et al. 2017. Marker allele corresponds to the S-615 derived Qss.msub.3BL (blue highlight)

${ }^{b}$ E, Europe; IP, Iberian Peninsula; L, Levant; NA, North Africa; PGR, Persian Gulf; A, South/Central/East Asia

'Potential values range from 1.0 to 5.0

${ }^{\mathrm{d}}$ Genetic distance derived from Cavanagh et al. 2013 
Table 4 LS Mean \pm SE of wheat stem sawfly infestation, stem cutting, parasitism, and larval mortality in selected wheat landrace accessions. Mean averaged over four environments, Loma 2013, Loma 2014, Amsterdam 2014, and Amsterdam 2015

\begin{tabular}{|c|c|c|c|c|c|c|}
\hline Country & Plant ID & Infestation (\%) & Stem cutting (\%) & Parasitism (\%) & Mortality (\%) & $\begin{array}{c}\text { Qss.msub.3BL } \\
\text { haplotype }\end{array}$ \\
\hline \multirow[t]{2}{*}{ Iran } & PI623445-1 & $29.94 \pm 7.70$ & $3.85 \pm 1.52 *$ & $48.80 \pm 9.27$ & $35.06 \pm 9.43$ & $A C$ \\
\hline & PI623445-3 & $34.10 \pm 6.99$ & $5.60 \pm 1.66^{*}$ & $40.68 \pm 7.04$ & $39.94 \pm 7.75$ & $A C$ \\
\hline \multirow[t]{4}{*}{ Japan } & PI382150-1 & $23.82 \pm 6.84^{*}$ & $6.40 \pm 2.10 *$ & $43.55 \pm 9.20$ & $29.41 \pm 8.91$ & $\mathrm{~K}$ \\
\hline & PI382150-2 & $23.46 \pm 5.85^{*}$ & $4.88 \pm 1.55^{*}$ & $48.23 \pm 7.55$ & $26.89 \pm 7.10$ & K \\
\hline & PI382150-3 & $24.37 \pm 5.97^{*}$ & $6.02 \pm 1.75^{*}$ & $34.77 \pm 6.82$ & $36.60 \pm 7.57$ & K \\
\hline & PI382150-4 & $21.87 \pm 5.62^{*}$ & $4.64 \pm 1.57^{*}$ & $33.75 \pm 7.57$ & $38.80 \pm 8.50$ & $\mathrm{~K}$ \\
\hline \multirow[t]{2}{*}{ Tajikistan } & PI639349-1 & $33.67 \pm 6.98$ & $11.28 \pm 2.70^{*}$ & $38.29 \pm 6.96$ & $26.56 \pm 6.73$ & $A B$ \\
\hline & PI639349-4 & $35.39 \pm 8.30$ & $8.74 \pm 2.60 *$ & $38.49 \pm 9.03$ & $35.01 \pm 9.43$ & $\mathrm{~T}$ \\
\hline \multirow[t]{12}{*}{ Turkey } & PI177946-2 & $30.41 \pm 7.76$ & $4.72 \pm 1.73^{*}$ & $39.85 \pm 9.08$ & $41.87 \pm 9.81$ & $\mathrm{C}$ \\
\hline & PI576680-2 & $13.00 \pm 4.55^{*}$ & $1.60 \pm 0.92 *$ & $51.94 \pm 9.27$ & $32.50 \pm 9.00$ & $\mathrm{C}$ \\
\hline & PI576680-3 & $17.50 \pm 5.45^{*}$ & $0.81 \pm 0.70^{*}$ & $51.11 \pm 10.18$ & $43.40 \pm 10.30$ & C \\
\hline & PI576688-1 & $27.84 \pm 7.43$ & $3.05 \pm 1.31^{*}$ & $39.37 \pm 9.06$ & $46.42 \pm 9.93$ & C \\
\hline & PI576688-2 & $31.43 \pm 7.88$ & $3.15 \pm 1.34^{*}$ & $26.58 \pm 8.18$ & $48.97 \pm 9.94^{*}$ & $\mathrm{C}$ \\
\hline & PI576688-4 & $36.16 \pm 8.36$ & $4.22 \pm 1.61^{*}$ & $49.98 \pm 9.27$ & $39.70 \pm 9.72$ & C \\
\hline & PI166331-4 & $17.47 \pm 5.72 *$ & $3.63 \pm 1.78^{*}$ & $44.52 \pm 11.32$ & $38.19 \pm 10.94$ & $\mathrm{~J}$ \\
\hline & PI166335-1 & $31.77 \pm 7.92$ & $4.75 \pm 1.73 *$ & $38.50 \pm 9.03$ & $31.42 \pm 9.12$ & C \\
\hline & PI166471-1 & $24.29 \pm 5.96^{*}$ & $3.90 \pm 1.36^{*}$ & $47.07 \pm 7.54$ & $35.42 \pm 7.81$ & C \\
\hline & PI166477-2 & $13.07 \pm 4.15^{*}$ & $1.60 \pm 0.86^{*}$ & $55.28 \pm 7.98$ & $34.83 \pm 7.92$ & C \\
\hline & PI178055-1 & $23.10 \pm 6.73^{*}$ & $2.64 \pm 1.31^{*}$ & $60.70 \pm 9.94^{*}$ & $19.09 \pm 9.36$ & C \\
\hline & PI178055-2 & $31.67 \pm 7.90$ & $5.20 \pm 1.84^{*}$ & $32.17 \pm 8.66$ & $29.47 \pm 8.92$ & C \\
\hline \multirow[t]{3}{*}{ Turkmenistan } & PI565386-1 & $46.87 \pm 8.50$ & $10.37 \pm 2.77^{*}$ & $45.51 \pm 8.54$ & $34.25 \pm 8.76$ & $A D$ \\
\hline & PI565386-2 & $32.96 \pm 6.90$ & $2.11 \pm 0.90^{*}$ & $46.67 \pm 7.42$ & $47.85 \pm 7.97^{*}$ & $\mathrm{C}$ \\
\hline & PI565386-3 & $36.07 \pm 7.93$ & $3.23 \pm 1.30^{*}$ & $53.60 \pm 8.55$ & $34.73 \pm 8.79$ & $\mathrm{AC}$ \\
\hline $\begin{array}{l}\text { Nepal (susceptible } \\
\text { accession) }\end{array}$ & PI406517-4 & $44.11 \pm 8.05$ & $25.55 \pm 5.24$ & $31.28 \pm 8.57$ & $23.46 \pm 7.64$ & $\mathrm{C}$ \\
\hline $\begin{array}{l}\text { USA (susceptible } \\
\text { varieties) }\end{array}$ & $\begin{array}{c}\text { Reeder \& } \\
\text { McNeal }\end{array}$ & $20.90 \pm 5.35$ & $12.54 \pm 3.58$ & $24.60 \pm 9.93$ & $29.58 \pm 5.71$ & $\mathrm{C}$ \\
\hline
\end{tabular}


*Significantly different from susceptible accession from Nepal according to $t$ test (LSD) at $P=0.05$. Plant IDs with same PI represent seeds from different wheat heads 
Supplemental Table 1. Wheat stem sawfly resistant wheat landrace accessions, their origin, resistance type, and solid stem haplotype

\begin{tabular}{|c|c|c|c|c|}
\hline Plant ID & Region & Country & $\begin{array}{c}\text { Resistance } \\
\text { type }^{\mathrm{a}}\end{array}$ & $\begin{array}{c}\text { Qss.msub.3BL } \\
\text { haplotype }\end{array}$ \\
\hline PI184583 & Europe & France & $A B$ & C \\
\hline PI191932 & Europe & France & $A B \& A X$ & C \\
\hline PI25748 & Europe & Germany & $A B \& A X$ & $\mathrm{~T}$ \\
\hline PI94570 & Europe & Greece & $A B \& A X$ & $A$ \\
\hline PI184566 & Iberian Peninsula & Portugal & $A B$ & C \\
\hline PI184572 & Iberian Peninsula & Portugal & $A B \& A X$ & C \\
\hline PI184573 & Iberian Peninsula & Portugal & $A B \& A X$ & C \\
\hline PI185204 & Iberian Peninsula & Portugal & $A X$ & C \\
\hline PI185208 & Iberian Peninsula & Portugal & $A B \& A X$ & $A C$ \\
\hline PI185332 & Iberian Peninsula & Portugal & $A X$ & $A B$ \\
\hline PI185334 & Iberian Peninsula & Portugal & $A X$ & $\mathrm{~T}$ \\
\hline PI185709 & Iberian Peninsula & Portugal & $A B$ & $A$ \\
\hline PI185714 & Iberian Peninsula & Portugal & $A B \& A X$ & $A$ \\
\hline PI185715 & Iberian Peninsula & Portugal & $A B \& A X$ & $A C$ \\
\hline PI185716 & Iberian Peninsula & Portugal & $A B \& A X$ & C \\
\hline PI191101 & Iberian Peninsula & Spain & $A B \& A X$ & C \\
\hline PI191122 & Iberian Peninsula & Spain & $A X$ & C \\
\hline PI191507 & Iberian Peninsula & Spain & $A B \& A X$ & $A$ \\
\hline PI191687 & Iberian Peninsula & Spain & $A B \& A X$ & $A$ \\
\hline PI192096 & Iberian Peninsula & Spain & $A B \& A X$ & $A A$ \\
\hline PI192206 & Iberian Peninsula & Portugal & $A X$ & $A$ \\
\hline PI192321 & Iberian Peninsula & Portugal & $A B$ & C \\
\hline PI192434 & Iberian Peninsula & Portugal & $A X$ & $A B$ \\
\hline PI192461 & Iberian Peninsula & Spain & $A B \& A X$ & $A C$ \\
\hline PI192599 & Iberian Peninsula & Portugal & $A B$ & C \\
\hline PI192768 & Iberian Peninsula & Portugal & $A B \& A X$ & $A C$ \\
\hline PI192793 & Iberian Peninsula & Portugal & $A B$ & $A C$ \\
\hline PI192802 & Iberian Peninsula & Portugal & UD & $A$ \\
\hline
\end{tabular}




\begin{tabular}{|c|c|c|c|c|}
\hline PI192856 & Iberian Peninsula & Portugal & $A X$ & \\
\hline PI203984 & Iberian Peninsula & Portugal & $A B \& A X$ & C \\
\hline PI203988 & Iberian Peninsula & Portugal & $A B$ & $A$ \\
\hline PI203995 & Iberian Peninsula & Portugal & UD & C \\
\hline PI203999 & Iberian Peninsula & Portugal & $A B$ & $\mathrm{AF}$ \\
\hline PI204000 & Iberian Peninsula & Portugal & $A B$ & $\mathrm{~T}$ \\
\hline PI204005 & Iberian Peninsula & Portugal & $A B$ & C \\
\hline PI204006 & Iberian Peninsula & Portugal & $A X$ & $A D$ \\
\hline PI266894 & Iberian Peninsula & Portugal & $A X$ & C \\
\hline PI266903 & Iberian Peninsula & Portugal & $A X$ & C \\
\hline PI278407 & Iberian Peninsula & Portugal & $A B$ & \\
\hline PI56237 & Iberian Peninsula & Portugal & $A B$ & C \\
\hline PI94585 & Iberian Peninsula & Portugal & $A B \& A X$ & $A$ \\
\hline PI117499 & Iberian Peninsula & Portugal & $A B \& A X$ & $A B$ \\
\hline PI134860 & Iberian Peninsula & Portugal & $A X$ & C \\
\hline PI134869 & Iberian Peninsula & Portugal & $A B \& A X$ & $\mathrm{AF}$ \\
\hline PI134879 & Iberian Peninsula & Portugal & $A B \& A X$ & $\mathrm{~T}$ \\
\hline PI134903 & Iberian Peninsula & Portugal & $A B \& A X$ & C \\
\hline PI166632 & Levant & Turkey & $A X$ & $\mathrm{~N}$ \\
\hline PI166942 & Levant & Turkey & $A B \& A X$ & C \\
\hline PI166951 & Levant & Turkey & $A B \& A X$ & $C$ \\
\hline PI167494 & Levant & Turkey & $A B \& A X$ & A \\
\hline PI167575 & Levant & Turkey & $A B \& A X$ & $A C$ \\
\hline PI167660 & Levant & Turkey & $A B \& A X$ & $\mathrm{~N}$ \\
\hline PI167664 & Levant & Turkey & $A B \& A X$ & $\mathrm{~N}$ \\
\hline PI172547 & Levant & Turkey & $A B \& A X$ & \\
\hline PI172548 & Levant & Turkey & $A B \& A X$ & A \\
\hline PI172554 & Levant & Turkey & $A B \& A X$ & $\mathrm{AF}$ \\
\hline PI173491 & Levant & Turkey & $A B$ & $\mathrm{C}$ \\
\hline PI177946-2 & Levant & Turkey & $A B$ & $C$ \\
\hline PI182899 & Levant & Turkey & $A B \& A X$ & C \\
\hline
\end{tabular}




\begin{tabular}{|c|c|c|c|c|}
\hline PI183856 & Levant & Turkey & $A X$ & $C$ \\
\hline PI183857 & Levant & Turkey & $A B \& A X$ & C \\
\hline PI178055-1 & Levant & Turkey & $A B$ & C \\
\hline PI178055-2 & Levant & Turkey & $A B$ & C \\
\hline PI178075 & Levant & Turkey & UD & C \\
\hline PI341361 & Levant & Turkey & $A B$ & C \\
\hline PI341619 & Levant & Turkey & $A B \& A X$ & C \\
\hline PI341657 & Levant & Turkey & $A B \& A X$ & C \\
\hline PI341658 & Levant & Turkey & $A B \& A X$ & C \\
\hline PI341662 & Levant & Turkey & $A B \& A X$ & C \\
\hline PI341740 & Levant & Turkey & $A X$ & $\mathrm{AF}$ \\
\hline PI341625 & Levant & Turkey & UD & $P$ \\
\hline PI520093 & Levant & Turkey & UD & $A B$ \\
\hline PI537968 & Levant & Turkey & $A B$ & C \\
\hline PI537969 & Levant & Turkey & $A X$ & A \\
\hline PI537972 & Levant & Turkey & $A B \& A X$ & $A B$ \\
\hline PI537974 & Levant & Turkey & $A B$ & C \\
\hline PI537974 & Levant & Turkey & $A B$ & \\
\hline PI537975 & Levant & Turkey & $A B$ & M \\
\hline PI576662 & Levant & Turkey & $A B \& A X$ & \\
\hline PI576662 & Levant & Turkey & $A B \& A X$ & $A C$ \\
\hline PI576674 & Levant & Turkey & $A X$ & C \\
\hline PI576675 & Levant & Turkey & UD & J, W \\
\hline PI576680-2 & Levant & Turkey & $A B \& A X$ & C \\
\hline PI576680-3 & Levant & Turkey & $A X$ & C \\
\hline PI576688-1 & Levant & Turkey & $A B$ & C \\
\hline PI576688-2 & Levant & Turkey & $A B$ & C \\
\hline PI576688-4 & Levant & Turkey & $A B$ & C \\
\hline PI278536 & Levant & Syria & UD & \\
\hline PI166280 & Levant & Turkey & UD & C \\
\hline PI94568 & Levant & Israel & $A B \& A X$ & A \\
\hline
\end{tabular}




\begin{tabular}{|c|c|c|c|c|}
\hline PI117421 & Levant & Turkey & $A B \& A X$ & $C$ \\
\hline PI119302 & Levant & Turkey & $A B \& A X$ & $C$ \\
\hline PI119316 & Levant & Turkey & $A B \& A X$ & $C$ \\
\hline PI119342 & Levant & Turkey & $A B \& A X$ & $\mathrm{~T}$ \\
\hline PI165115 & Levant & Turkey & $A B \& A X$ & $C$ \\
\hline PI166331-4 & Levant & Turkey & $A B \& A X$ & $J, W$ \\
\hline PI166335-1 & Levant & Turkey & $A B$ & $C$ \\
\hline PI166471-1 & Levant & Turkey & $A B \& A X$ & $C$ \\
\hline PI166477-2 & Levant & Turkey & $A B \& A X$ & $C$ \\
\hline PI166562 & Levant & Turkey & $A X$ & $C$ \\
\hline PI166565 & Levant & Turkey & $A X$ & $C$ \\
\hline PI166572 & Levant & Turkey & $A B \& A X$ & $C$ \\
\hline PI191402 & North Africa & Morocco & $A B \& A X$ & $A$ \\
\hline PI525212 & North Africa & Morocco & $A X$ & $A$ \\
\hline PI525213 & North Africa & Morocco & $A B$ & $A$ \\
\hline PI525218 & North Africa & Morocco & $A B \& A X$ & $\mathrm{~N}$ \\
\hline PI525220 & North Africa & Morocco & $A B \& A X$ & $C$ \\
\hline PI525239 & North Africa & Morocco & $A B \& A X$ & $A C$ \\
\hline PI525243 & North Africa & Morocco & $A X$ & $M$ \\
\hline PI525246 & North Africa & Morocco & $A B \& A X$ & $M$ \\
\hline PI525247 & North Africa & Morocco & $A B \& A X$ & $\mathrm{AE}$ \\
\hline PI525250 & North Africa & Morocco & $A X$ & $M$ \\
\hline PI525251 & North Africa & Morocco & $A B \& A X$ & M \\
\hline PI525261 & North Africa & Morocco & $A X$ & $A$ \\
\hline PI525264 & North Africa & Morocco & $A B \& A X$ & $M$ \\
\hline PI525280 & North Africa & Morocco & $A B$ & $A$ \\
\hline PI525284 & North Africa & Morocco & $A X$ & $A$ \\
\hline PI525293 & North Africa & Morocco & $A B \& A X$ & $\mathrm{M}$ \\
\hline PI525301 & North Africa & Morocco & $A B$ & $A C$ \\
\hline PI525304 & North Africa & Morocco & $A B \& A X$ & $A$ \\
\hline PI525305 & North Africa & Morocco & $A B$ & $A$ \\
\hline
\end{tabular}




\begin{tabular}{|c|c|c|c|c|}
\hline PI525309 & North Africa & Morocco & $A X$ & $A$ \\
\hline PI525311 & North Africa & Morocco & UD & $A C$ \\
\hline PI525324 & North Africa & Morocco & $A B \& A X$ & $A$ \\
\hline PI525326 & North Africa & Morocco & $A B \& A X$ & $A$ \\
\hline PI525346 & North Africa & Morocco & $A X$ & $M$ \\
\hline PI525434 & North Africa & Morocco & $A X$ & $A$ \\
\hline PI525439 & North Africa & Morocco & $A B$ & $A E$ \\
\hline PI559967 & North Africa & Morocco & $A B$ & $\mathrm{~J}, \mathrm{~W}$ \\
\hline PI210853 & Persian Gulf & Iran & $A B$ & $A C$ \\
\hline PI222669 & Persian Gulf & Iran & UD & $A C$ \\
\hline PI222677 & Persian Gulf & Iran & $A B$ & $\mathrm{C}$ \\
\hline PI222683 & Persian Gulf & Iran & $A B \& A X$ & $A C$ \\
\hline PI222684 & Persian Gulf & Iran & $A X$ & B \\
\hline PI243731 & Persian Gulf & Iran & $A B$ & S \\
\hline PI243732 & Persian Gulf & Iran & $A X$ & $\mathrm{C}$ \\
\hline PI243744 & Persian Gulf & Iran & $A B \& A X$ & $\mathrm{C}$ \\
\hline PI623131 & Persian Gulf & Iran & $A B$ & B \\
\hline PI623161 & Persian Gulf & Iran & $A B$ & $\mathrm{~N}$ \\
\hline PI623162 & Persian Gulf & Iran & $A B \& A X$ & $\mathrm{~N}$ \\
\hline PI623396 & Persian Gulf & Iran & $A B \& A X$ & $A C$ \\
\hline PI623397 & Persian Gulf & Iran & $A B \& A X$ & $\mathrm{C}$ \\
\hline PI623440 & Persian Gulf & Iran & $A X$ & $A$ \\
\hline PI623520 & Persian Gulf & Iran & $A X$ & $\mathrm{C}$ \\
\hline PI623521 & Persian Gulf & Iran & $A B$ & $\mathrm{C}$ \\
\hline PI623522 & Persian Gulf & Iran & $A B$ & $\mathrm{C}$ \\
\hline PI623527 & Persian Gulf & Iran & $A B \& A X$ & \\
\hline PI623535 & Persian Gulf & Iran & $A B$ & $\mathrm{C}$ \\
\hline PI623542 & Persian Gulf & Iran & $A B \& A X$ & $\mathrm{C}$ \\
\hline PI623554 & Persian Gulf & Iran & $A X$ & $\mathrm{C}$ \\
\hline PI623564 & Persian Gulf & Iran & $A B \& A X$ & $\mathrm{C}$ \\
\hline PI623571 & Persian Gulf & Iran & $A B \& A X$ & \\
\hline
\end{tabular}




\begin{tabular}{|c|c|c|c|c|}
\hline PI623589 & Persian Gulf & Iran & $A B$ & C \\
\hline PI623592 & Persian Gulf & Iran & $A B \& A X$ & \\
\hline PI623599 & Persian Gulf & Iran & $A B$ & $\mathrm{C}$ \\
\hline PI623628 & Persian Gulf & Iran & $A B$ & $\mathrm{C}$ \\
\hline PI623631 & Persian Gulf & Iran & $A B \& A X$ & $A C$ \\
\hline PI623674 & Persian Gulf & Iran & $A B \& A X$ & $\mathrm{C}$ \\
\hline PI623708 & Persian Gulf & Iran & $A B \& A X$ & \\
\hline PI623753 & Persian Gulf & Iran & $A B \& A X$ & $A$ \\
\hline PI623754 & Persian Gulf & Iran & $A B \& A X$ & $A C$ \\
\hline PI623856 & Persian Gulf & Iran & $A B$ & $A C$ \\
\hline PI626588 & Persian Gulf & Iran & $A B \& A X$ & $\mathrm{~N}$ \\
\hline PI623445-2 & Persian Gulf & Iran & $A B$ & $A C$ \\
\hline PI623445-3 & Persian Gulf & Iran & $A B$ & $A C$ \\
\hline PI142515 & Persian Gulf & Iran & $A B \& A X$ & $A C$ \\
\hline PI142516 & Persian Gulf & Iran & $A X$ & $A C$ \\
\hline PI182583 & South/Central/East Asia & Japan & $A B \& A X$ & $A B$ \\
\hline PI197128 & South/Central/East Asia & Japan & $A X$ & \\
\hline PI262611 & South/Central/East Asia & Turkmenistan & UD & $A$ \\
\hline PI262621 & South/Central/East Asia & Ukraine & $A B$ & $\mathrm{~T}$ \\
\hline PI262623 & South/Central/East Asia & Georgia & UD & $P$ \\
\hline PI262628 & South/Central/East Asia & Georgia & $A B$ & $A D$ \\
\hline PI262678 & South/Central/East Asia & Georgia & $A B \& A X$ & $\mathrm{C}$ \\
\hline PI372124 & South/Central/East Asia & Armenia & $A B$ & $\mathrm{C}$ \\
\hline PI390909 & South/Central/East Asia & China & $A B$ & $E$ \\
\hline PI409010 & South/Central/East Asia & Japan & $A X$ & $\mathrm{~J}, \mathrm{~W}$ \\
\hline PI499971 & South/Central/East Asia & Georgia & $A B$ & $\mathrm{C}$ \\
\hline PI525211 & South/Central/East Asia & Georgia & $A X$ & $A$ \\
\hline PI565386-3 & South/Central/East Asia & Turkmenistan & $A B$ & $A B$ \\
\hline PI565386-1 & South/Central/East Asia & Turkmenistan & $A B$ & $A D$ \\
\hline PI565386-2 & South/Central/East Asia & Turkmenistan & $A B$ & $\mathrm{C}$ \\
\hline PI565386 & South/Central/East Asia & Turkmenistan & $A B$ & C \\
\hline
\end{tabular}




PI585016
PI639304
PI639308
PI639349-1
PI639349-4
CItr7599
PI65110
PI69231
PI69249
PI69257
PI69263
PI69270
PI382150
PI382150-2
PI382150-1
PI382150-3
PI382150-4
PI406517
PI69327
PI69741
PI69761
PI69771
PI70313
PI70586
PI70587
PI70661
PI70667
PI72080
PI72762
PI74801
PI83237

South/Central/East Asia South/Central/East Asia

China South/Central/East Asia South/Central/East Asia

China

Japan South/Central/East Asia

Japan South/Central/East Asia South/Central/East Asia

Japan

Japan

South/Central/East Asia

Japan South/Central/East Asia South/Central/East Asia South/Central/East Asia

Nepal

China

China

South/Central/East Asia

China South/Central/East Asia South/Central/East Asia South/Central/East Asia

China

China

China South/Central/East Asia

China South/Central/East Asia South/Central/East Asia South/Central/East Asia South/Central/East Asia South/Central/East Asia South/Central/East Asia

China

China

China

China

China

China

$\begin{array}{cc}A B & P \\ A B & A B \\ A B & T \\ A B \& A X & C \\ U D & A C \\ A B \& A X & C \\ A X & A C \\ U D & A C \\ A X & A C \\ A B \& A X & C \\ A B \& A X & K \\ A B & K \\ A B \& A X & K \\ A B \& A X & K \\ A B \& A X & K \\ A B & \end{array}$

$A B$

$A X$

$A B \& A X$ $A B$

$A B$ \& $A X$

$A B \& A X$

$A B \& A X$

$A B \& A X$

$A B$

$A B \& A X$

$A B \& A X$

UD

$A B$ \& $A X$

$A X$

$A C$

$A C$

$A C$

$C$ 
PI94590

South/Central/East Asia

${ }^{a} A B$, antibiosis; $A X$, antixenosis; UD, undetermined 